\title{
Endocrinological Outcomes of Intraoperative MRI-Guided Endoscopic Transsphenoidal Surgery for Non-Functioning Pituitary Adenoma
}

\author{
ZhiBin ZHANG ${ }^{1,2}$, Peng WANG ${ }^{1}$, ShiYu FENG ${ }^{1}$, XinGuang YU \\ ${ }^{1}$ Chinese PLA General Hospital, Department of Neurosurgery, Beijing, China \\ ${ }^{2}$ Nankai University, School of Medicine, Tianjin, China \\ Corresponding author: XinGuang YU xinguang_yu@263.net
}

\section{ABSTRACT}

AIM: To assess the endocrinological outcomes of high-field (1.5-T) intraoperative magnetic resonance imaging (iMRI)-guided endoscopic transsphenoidal surgery (TSS) for non-functioning pituitary adenomas (NFPAs).

MATERIAL and METHODS: Radiological and endocrinological data were retrospectively collected and analyzed for 133 consecutive patients who underwent iMRI-guided endoscopic TSS for NFPA.

RESULTS: Between the first and final scans, the gross total resection (GTR) rate increased from $42.9 \%$ to $63.9 \%$. Preoperatively, 105 patients were deficient in at least 1 pituitary hormone axis (corticotroph axis: 51 patients, gonadotrope axis: 89 patients, thyrotrope axis: 51 patients, growth hormone axis: 19 patients). After surgery, varying rates of improvement were observed in patients with deficiencies in the growth hormone (89.5\%), corticotroph (78.4\%), gonadotrope (49.4\%), and thyrotrope axes (33.3\%). Pituitary function deteriorated in 75 patients (corticotroph axis: 23 patients, gonadotrope axis: 30 , thyrotrope axis: 56 patients). Univariate logistic regression analyses revealed that, among patients with hypopituitarism of the gonadotrope axis, women were more likely than men to experience recovery (odds ratio [OR]: $0.417,95 \%$ confidence interval $[\mathrm{Cl}]: 0.191-0.913 ; p=0.029$ ) and not experience deterioration (OR: 2.539, 95\% Cl: 1.057-6.098; $p=0.037$ ). The increased GTR rate, based on the iMRI findings, was not associated with an increased incidence of postoperative hypopituitarism or lower recovery rates in the pituitary axes (both $p>0.05$ ).

CONCLUSION: The GTR rate for NFPAs was increased using iMRI, although this increase was not associated with improvement or deterioration of hypopituitarism.

KEYWORDS: Intraoperative MRI, Endoscope, Pituitary, NFPAs, Hypopituitarism, Surgery

\section{INTRODUCTION}

$\mathrm{N}$ on-functioning pituitary adenomas (NFPAs) are the most common pituitary adenomas (approximately one-third of all cases) $(19,22)$. Because hormonal hypersecretion syndromes are often absent in cases of NFPA, these cases are usually diagnosed when the adjacent anatomical structures are compressed and the patient experiences related events, such as headache, visual disturbances, and/or impaired pituitary function (23). Hormonal deficiencies gradually evolve and eventually become the leading signs and symptoms at presentation in these cases (16). Postoperative adenoma remnants are a risk factor for adenoma recurrence and postoperative hypopituitarism (14), which highlights the importance of regular follow-up examinations and medication. Thus, in patients with NFPA and hypopituitarism, gross total resection (GTR) and restoration of pituitary function are
ZhiBin ZHANG (10): 0000-0003-2502-7034 Peng WANG : 0000-0003-0649-3240
ShiYu FENG (1): 0000-0002-5787-402X

XinGuang YU (D) : 0000-0003-4719-6488 
recommended. However, surgical treatment of NFPA remains challenging, given the incidence of suprasellar and cavernous sinus extension (38), and the high rate of unsuspected tumor remnants $(4,30)$.

Endoscopic transsphenoidal surgery (TSS) has become a popular procedure in hospitals throughout the world $(35,39)$. Its advantages include better illumination, which provides the neurosurgeon with a better view of the sellar, parasellar, and suprasellar regions. However, morphological assessment of resection radicality remains necessary. Several intraoperative procedures have been devised to achieve better postoperative results. In this context, modern intraoperative magnetic resonance imaging (iMRI) is a remarkable technique that was revolutionized by the pioneering efforts of Black et al. in the 1990s (7). This technique provides real-time feedback during the procedure and continuously updates the archived images for most widely used neuronavigation systems (11), which helps improve the GTR rate (12). Therefore, iMRI-guided procedures may help improve pituitary function recovery by eliminating the need to probe for tumor remnants, which can harm the pituitary gland and affect its function. Although Nimsky et al. reported a series of iMRl-guided operations for hormonally inactive pituitary macro-adenomas in 2006 (27), few subsequent studies have evaluated the effects of iMRI on the GTR rate and the endocrinological changes after TSS for NFPAs. This retrospective study evaluated consecutive patients to determine whether high-field iMRI influenced the success of resection and endocrinological outcomes after endoscopic TSS for NFPAs.

\section{- MATERIAL and METHODS}

Between January 2011 and December 2013, 133 patients with NFPAs were treated by a single neurosurgeon (XHM) at our department. All procedures were performed with the assistance of an endoscope and high-field (1.5-T) iMRI. Patients were excluded if they had a history of previous therapies, such as irradiation or dopamine agonist treatment.

\section{Preoperative and Postoperative Endocrinological Assessments}

Preoperative and postoperative blood tests were performed for all patients to detect changes in their anterior pituitary hormone levels. In all cases, an endocrinologist identified any endocrinological changes based on pre-defined assessment criteria. Hypothalamic-pituitary-adrenal axis deficiency was defined as morning (09:00) serum cortisol levels below the normal range (198.7-797.5 nmol/L) or peak cortisol levels of $<450 \mathrm{nmol} / \mathrm{L}$ after an insulin tolerance test. Thyrotrope axis deficiency was defined as levels below the normal range for serum-free T4 (normal range: 10.42-24.32pmol/L) and/or T4 (normal range: 55.34-160.88 nmol/L). For male patients, gonadotrope axis deficiency was defined as serum testosterone levels below the normal range $(8.4-28.7 \mathrm{nmol} / \mathrm{L})$ with low or normal levels of luteinizing hormone (normal range for 19-70 years old: 1.5-9.3 IU/L; >70 years old: 3.1-34.6 $\mathrm{IU} / \mathrm{L})$ or follicle-stimulating hormone (1.4-18.1 IU/L). For premenopausal female patients, gonadotropin axis deficiency was defined as gonadotropin levels below the normal range (luteinizing hormone: $0.5-76.3 \mathrm{mIU} / \mathrm{mL}$; follicle-stimulating hormone: 1.5-33.4 IU/L) plus estradiol levels that were persistently below the normal range (48.2-1,531.9 pmol/L). For postmenopausal female patients, the normal ranges were defined as 15.9-54.0 mlU/mL for luteinizing hormone and 23$116.3 \mathrm{IU} / \mathrm{L}$ for follicle-stimulating hormone. A gonadotropinreleasing hormone test (100 $\mu \mathrm{g}$ intravenously) was performed for unclear cases, with growth hormone deficiency defined as a peak of $<5 \mu \mathrm{g} / \mathrm{L}$ after a glucose/insulin tolerance test.

\section{Radiological Assessments}

All patients underwent preoperative, intraoperative, and postoperative contrast-enhanced MRI. Tumor volumes and diameters were assessed using software (iPlan 3.0; BrainLAB, Feldkirchen, Germany). Patients were classified according to Hardy's system as having a grade I tumor (diameter: $<10$ $\mathrm{mm}$ ), a grade II tumor (diameter: 10-20 mm and suprasellar extension within $10 \mathrm{~mm}$ of the sphenoidal plane), a grade III tumor (diameter: 20-40 $\mathrm{mm}$ and suprasellar extension up to $30 \mathrm{~mm}$ ), or agrade IV tumor (diameter: $>40 \mathrm{~mm}$ and extension far beyond the sellar space) $(3,15)$. Because most tumors were large or had invaded the surrounding structures, the cohort was divided into two groups: planned GTR and planned subtotal resection. Successful GTR was defined as no visible tumor during the intraoperative assessment and at the 3-month postoperative MRI evaluation.

\section{iMRI and Surgical Procedures}

While the patient remained still, ceiling-mounted rails were used to move the 1.5-T MRI device (Espree TM, Siemens, Germany) approximately $8 \mathrm{~m}$ between the operating room and the MRI diagnostic room, which were separated by a screening door with an air lock. After maximum tumor resection, surgical instruments and other ferromagnetic objects were moved outside the 5-gauss line. The iMRI device was then moved into the diagnostic room and the $\mathrm{IMRI}$ sequences were obtained.

Figure 1 shows the work flow of iMRl-guided surgery for NFPAs. Standard endoscopic TSS was performed by a single surgeon. All patients underwent preoperative MRI and the results were uploaded into the iPlan software. After the neurosurgeon declared that the resection was complete or that further resection could not safely be performed, the surgery was interrupted and $\mathrm{MRI}$ was performed. When the iMRI confirmed GTR, the surgery was completed with sellar reconstruction. When the results revealed safely accessible residual tumor tissue, further endoscopic inspection was performed after the iMRI scans were integrated into the navigation system. Figure $2 \mathrm{~A}-\mathrm{F}$ shows an example of how the iMRI was used to help treat NFPAs.

\section{Postoperative Assessment and Follow-up}

The first postoperative MR scan to detect tumor remnants in the sellar region was routinely performed at 3 months after surgery. The patients were asked to report any changes in their eyesight, field of vision, or any post-nasal drip (which might suggest a CSF leak). Postoperative neuro-ophthalmologic examinations were performed before the patient left the 


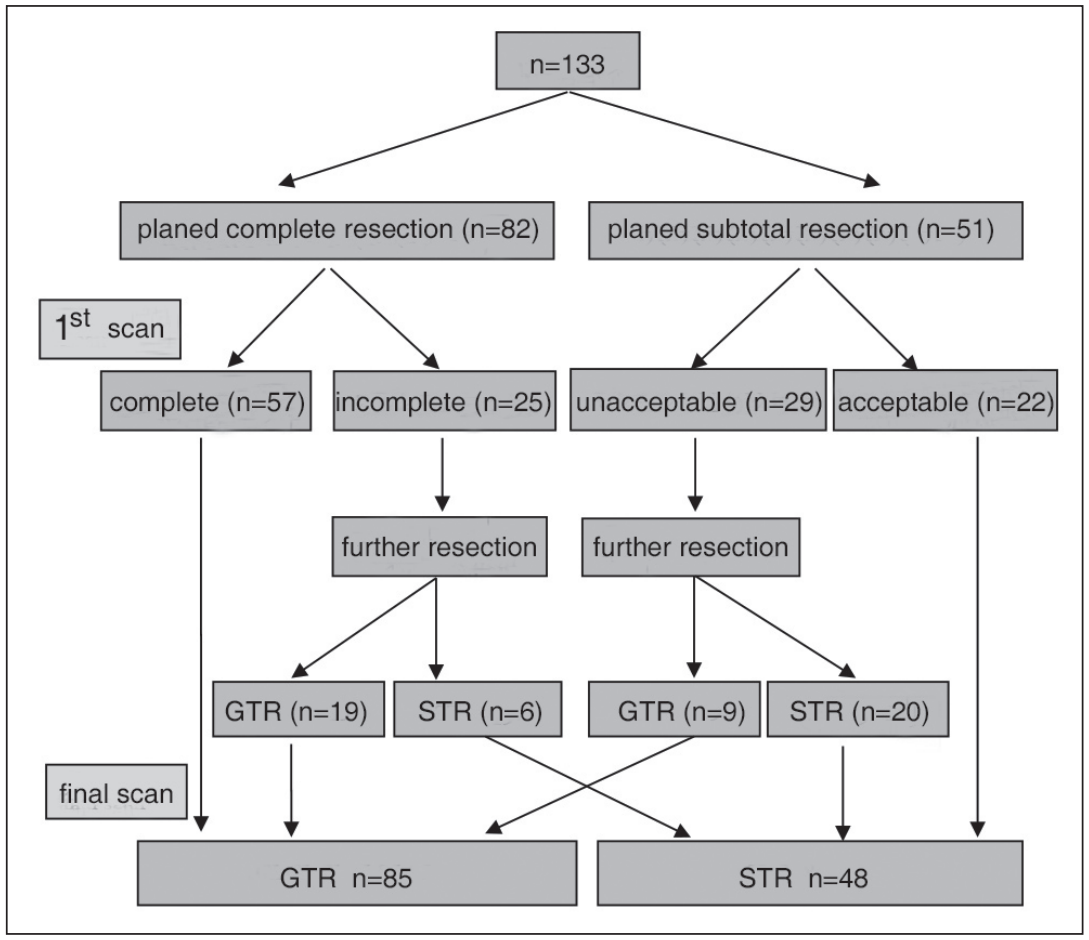

Figure 1: Work flow based on the intraoperative magnetic resonance imaging.
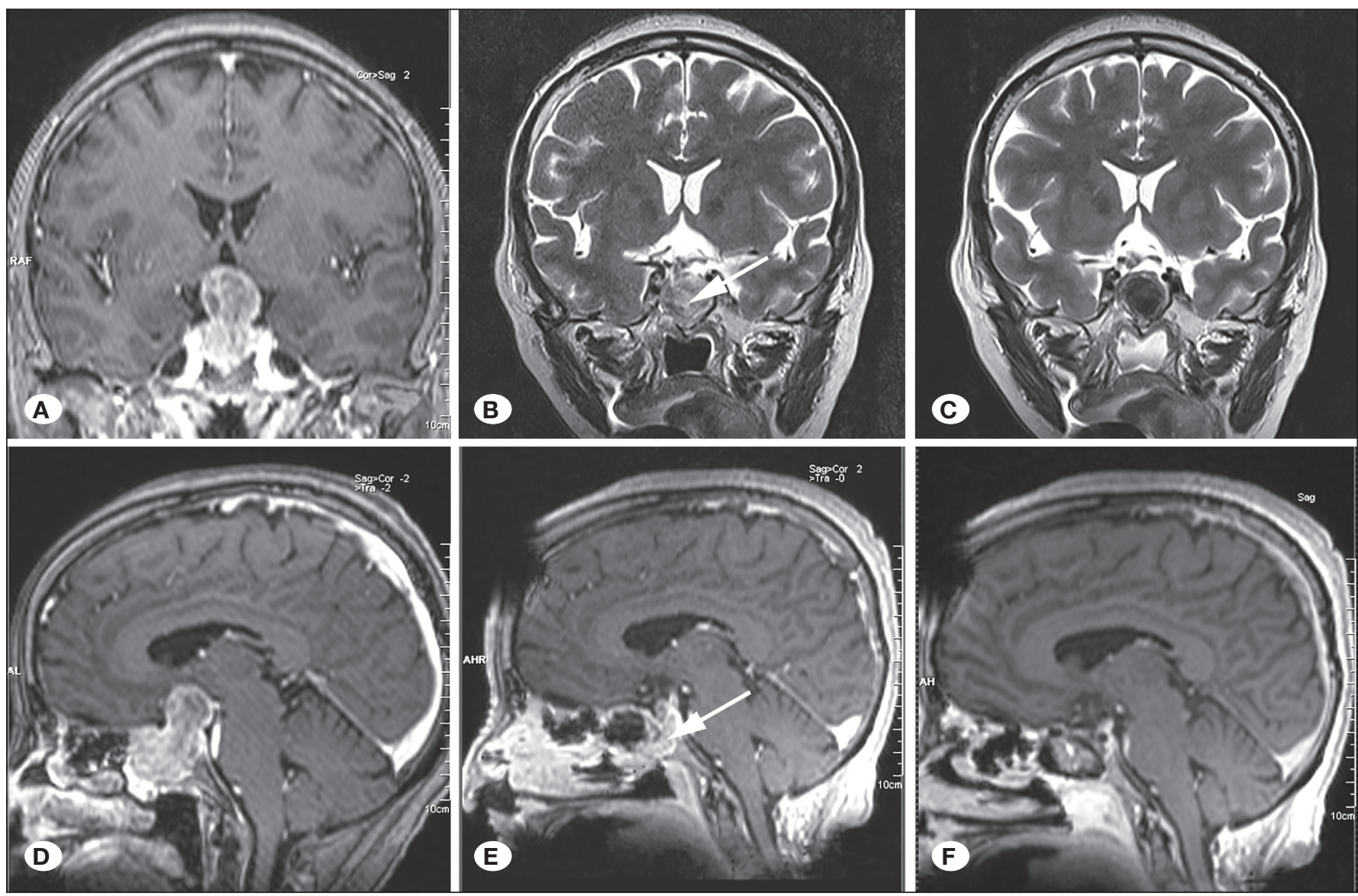

Figure 2: The intraoperative magnetic resonance imaging-guided endoscopic transsphenoidal surgery for a large nonfunctioning pituitary adenoma (the preoperative images, $\mathbf{A}$ and $\mathbf{D}$ ). The intraoperative images showed tumor remnants after the primary resection (B and $\mathbf{E}$, arrows). The intraoperative images after extended resection showed gross tumor resection (C and F). 
hospital and during the follow-up period. Postoperative endocrinological examinations were performed at 1 week after surgery. Clinical, endocrinological, and neuroradiological outcomes were assessed at 3-6 months postoperatively and then annually thereafter.

\section{Statistical Analysis}

Microsoft Excel (version 2007) and SPSS software (version 17.0; SPSS Inc., Chicago, IL) were used to perform all statistical analyses. Quantitative variables were reported as mean \pm standard deviation. Univariate logistic regression analyses were performed to identify variables to predicted changes in pituitary function, and the results were reported as odds ratiosand $95 \%$ confidence intervals. A two-tailed $\mathrm{p}$-value of $<0.05$ was considered statistically significant.

\section{RESULTS}

The iMRI quality was sufficient to show the extent of resection and all surrounding anatomical structures (i.e., the normal pituitary gland, internal carotid artery, optic apparatus, and pituitary stalk). The total number of scans ranged from 1 to 4 (mean:1.3 \pm 0.5 ), excluding the initial scan that was performed before the resection. The average time for each iMRI scan was $12.0 \pm 1.9 \mathrm{~min}$, which included the time required to prepare for intraoperative imaging and update the neuronavigation system. No adverse events or unanticipated side effects were observed. The extents of resection were identical in all cases based on the intraoperative and 3-month postoperative iMRI findings.

\section{Patient Characteristics and Preoperative Assessment}

The 133 consecutive patients included 61 men and 72 women (Table I). The mean age was $50 \pm 12$ years (range:18-80 years). Fifty-six patients reported experiencing dizziness and headaches. Ophthalmological examinations revealed that 100 patients had visual field defects and/or decreased visual acuity. Preoperative hypopituitarism was detected in 105 patients (78.9\%). Thirty-eight patients had prior surgical treatment. The average adenoma diameter was $3.4 \pm 0.9 \mathrm{~cm}$ (range: $1.3-5.8 \mathrm{~cm}$ ) and giant adenomas were found in 91 patients $(68.4 \%)$.

\section{Intraoperative Findings and Extent of Resection}

Figure 1 provides an overview of the outcomes after the iMRI. Eighty-two patients underwent planned GTR based on their clinicalor radiographic features. Fifty-seven patients (42.9\%) had no visible tumor remnants on their first high-field iMRI scans, while 54 patients (40.6\%) underwent further resection based on the first iMRI scan. The GTR rate increased from $42.9 \%(57 / 133)$ to $63.9 \%$ (85/133) when iMRI was used. Most remnant tumors were found in a suprasellar space attached to the optic apparatus and the third ventricle floor, invaded the cavernous sinus and surrounded the internal carotid artery, or located at the fold of the sellar diaphragm.

\section{Preoperative and Postoperative Pituitary Functions}

Preoperative hypopituitarism was detected in $78.9 \%$ of the patients (105/133). Fifty-one patients exhibited evidence of biochemical deficiency in the corticotroph axis, 89 patients exhibited deficiency in the gonadotrope axis, 51 patients exhibited deficiency in the thyrotropeaxis, and 19 patients exhibited deficiency in the growth hormoneaxis. Figure 3 shows the preoperative and postoperative prevalence of hypopituitarism in each axis.

The postoperative endocrinological outcomes are summarized in Table II. Varying rates of improvement were observed in patients with deficiencies in the growth hormoneaxis $(89.5 \%)$, the corticotroph axis (78.4\%), the gonadotrope axis $(49.4 \%)$, and the thyrotrope axis (33.3\%). Seventy-five patients exhibited deterioration in their pituitary function (23 patients in the corticotroph axis, 30 patients in the gonadotrope axis, and 56 patients in the thyrotrope axis).

Univariate analyses were performed to examine the predictive values of sex, age, extent of resection, tumor diameter, tumor volume, previous pituitary surgery, and pituitary apoplexy (Table III, IV). The results revealed that, among patients with hypopituitarism of the gonadotrope axis, female patients had higher recovery rates $(p=0.029)$ and lower deterioration rates $(p=0.037)$ than male patients. However, the detection of resection remnants using iMRI was not associated with a higher incidence of postoperative hypopituitarism or with a lower rate of pituitary deficit recovery.

Table I: Patient Characteristics and Preoperative Assessments

\begin{tabular}{lc}
\hline Variables & 133 \\
\hline No. of patients & $50 \pm 12(18-80)$ \\
\hline Mean age, years (range) & $61(45.9)$ \\
\hline Male sex & \\
\hline Symptoms and signs &
\end{tabular}

Visual field and/or visual acuity impairment

100 (75.2)

\begin{tabular}{lc}
\hline Dizziness and/or headache & $56(42.1)$ \\
\hline Hypopituitarism & $105(78.9)$ \\
\hline Others & $14(10.5)$ \\
\hline
\end{tabular}

Hardy's tumor grade

Grade I 6 (4.5)

Grade II $36(27.1)$

Grade III 60 (45.1)

Grade IV 31 (23.3)

\begin{tabular}{lc} 
Mean tumor diameter $(\mathrm{cm})$ & $3.4 \pm 0.9(1.3-5.8)$ \\
\hline Mean tumor volume $\left(\mathrm{cm}^{3}\right)$ & $15.6 \pm 10.6(2.3-70.5)$ \\
\hline
\end{tabular}

Previous pituitary adenoma resection

Follow-up, months (range)

$62 \pm 9.4(46-80)$

Data are shown as number (\%) or mean \pm standard deviation (range). 


\section{Follow-up}

All patients were hospitalized for an average of $7.4 \pm 5.4$ days and had an average follow-uptime of $62 \pm 9.4$ months. The preoperative headache disappeared in 45 patients $(80.4 \%)$

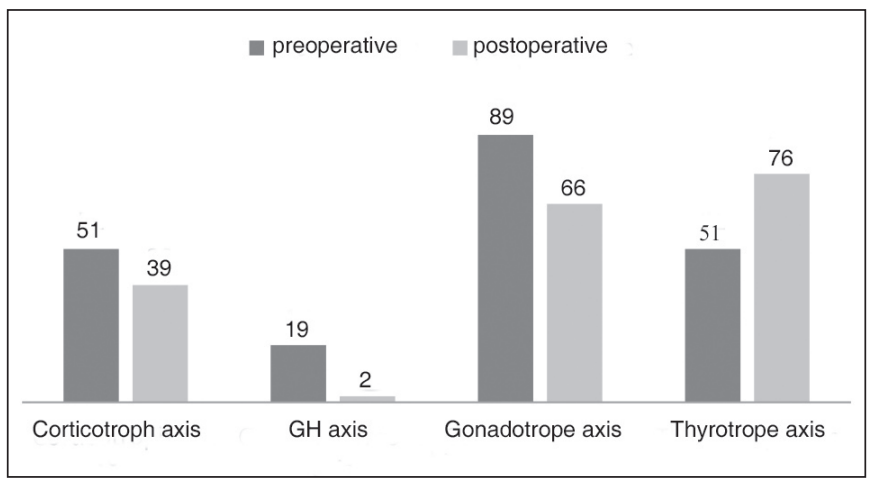

Figure 3: The prevalence of pituitary hormone deficiencies before and after surgery. within 3 days after surgery and in 50 cases (89.3\%) within the next 7 days. Ophthalmological follow-ups revealed improvement in the visual field deficits for 78 of 100 patients (78.0\%). One patient experienced worsening of the visual field deficit. Most patients exhibited recovery from their preoperative hypopituitarism. During the procedure, 24 patients had an intraoperatively detected CSF leak, and 15 of these patients were included in the 54 patients who underwent further resection after the first scan. The rate of CSF leak was only $11.4 \%$ (9/79) among patients without further resection. One patient experienced from long-term hypocortisolism, 3 patients experienced hypothyroidism, and 3 patients experienced both conditions.

\section{DISCUSSION}

The results from this retrospective study indicate that highfield iMRI can affect tumor resection and endocrinological outcomes after endoscopic TSS for NFPA. In this context, a greater extension of resection for NFPAs is associated with low recurrence rates and postoperative hypopituitarism

Table II: Postoperative Endocrinological Outcomes

\begin{tabular}{lcccc}
\hline & \multirow{2}{*}{$\begin{array}{c}\text { Preoperative } \\
\text { endocrine deficits }\end{array}$} & Improved & Unchanged & Worse \\
\cline { 3 - 5 } & 51 & 40 & 70 & 23 \\
\hline Corticotroph axis $(\mathrm{n})$ & 19 & 17 & 116 & 0 \\
\hline Growth hormone axis $(\mathrm{n})$ & 89 & 44 & 59 & 30 \\
\hline Gonadotrope axis $(\mathrm{n})$ & 51 & 17 & 60 & 56 \\
\hline Thyrotrope axis $(\mathrm{n})$ & & &
\end{tabular}

Table III: Univariate Analyses of Preoperative Pituitary Function Deficiency Improvement according to Demographic and Clinical Characteristics

\begin{tabular}{|c|c|c|c|c|c|c|c|c|}
\hline \multirow[b]{2}{*}{ Variables } & \multicolumn{2}{|c|}{ Corticotroph axis } & \multicolumn{2}{|l|}{ GH axis } & \multicolumn{2}{|c|}{ Gonadotrope axis } & \multicolumn{2}{|c|}{ Thyrotrope axis } \\
\hline & OR (95\% Cl) & $\mathbf{p}$ & OR $(95 \% \mathrm{Cl})$ & $\mathbf{p}$ & OR $(95 \% \mathrm{Cl})$ & $\mathbf{p}$ & OR $(95 \% \mathrm{Cl})$ & $\mathbf{p}$ \\
\hline Sex & $\begin{array}{c}1.317 \\
(0.597-2.907)\end{array}$ & 0.495 & $\begin{array}{c}2.214 \\
(0.770-6.367)\end{array}$ & 0.140 & $\begin{array}{c}0.417 \\
(0.191-0.913)\end{array}$ & 0.029 & $\begin{array}{c}0.451 \\
(0.141-1.439)\end{array}$ & 0.179 \\
\hline Age & $\begin{array}{c}1.026 \\
(0.992-1.061)\end{array}$ & 0.138 & $\begin{array}{c}1.017 \\
(0.972-1.063)\end{array}$ & 0.466 & $\begin{array}{c}0.998 \\
(0.967-1.030)\end{array}$ & 0.907 & $\begin{array}{c}1.042 \\
(0.993-1.094)\end{array}$ & 0.094 \\
\hline Extent of resection & $\begin{array}{c}0.536 \\
(0.221-1.299)\end{array}$ & 0.167 & $\begin{array}{c}1.495 \\
(0.498-4.488)\end{array}$ & 0.473 & $\begin{array}{c}1.525 \\
(0.676-3.440)\end{array}$ & 0.310 & $\begin{array}{c}1.826 \\
(0.603-5.529)\end{array}$ & 0.287 \\
\hline Tumor diameter & $\begin{array}{c}1.128 \\
(0.618-2.060) \\
\end{array}$ & 0.694 & $\begin{array}{c}1.257 \\
(0.541-2.920) \\
\end{array}$ & 0.594 & $\begin{array}{c}1.152 \\
(0.630-2.109) \\
\end{array}$ & 0.646 & $\begin{array}{c}1.116 \\
(0.476-2.620) \\
\end{array}$ & 0.801 \\
\hline Tumor volume & $\begin{array}{c}1.036 \\
(0.983-1.090)\end{array}$ & 0.185 & $\begin{array}{c}0.955 \\
(0.876-1.041)\end{array}$ & 0.299 & $\begin{array}{c}0.961 \\
(0.909-1.015)\end{array}$ & 0.156 & $\begin{array}{c}0.960 \\
(0.888-1.038)\end{array}$ & 0.310 \\
\hline $\begin{array}{l}\text { Previous pituitary } \\
\text { adenoma resection }\end{array}$ & $\begin{array}{c}0.422 \\
(0.174-1.026)\end{array}$ & 0.057 & $\begin{array}{c}0.675 \\
(0.210-2.166)\end{array}$ & 0.509 & $\begin{array}{c}1.457 \\
(0.594-3.572)\end{array}$ & 0.411 & $\begin{array}{c}0.494 \\
(0.151-1.615)\end{array}$ & 0.244 \\
\hline Pituitary apoplexy & $\begin{array}{c}1.102 \\
(0.347-3.507)\end{array}$ & 0.869 & $\begin{array}{c}3.202 \\
(0.381-26.905)\end{array}$ & 0.284 & $\begin{array}{c}0.930 \\
(0.320-2.704)\end{array}$ & 0.895 & $\begin{array}{c}2.609 \\
(0.305-22.319)\end{array}$ & 0.381 \\
\hline
\end{tabular}

OR: Odds ratio, Cl: Confidence interval. 
Table IV: Univariate Analyses of Features Potentially Associated with Postoperative Worse of Pituitary Function

\begin{tabular}{|c|c|c|c|c|c|c|}
\hline \multirow{2}{*}{ Variables } & \multicolumn{2}{|c|}{ Corticotroph axis } & \multicolumn{2}{|c|}{ Gonadotrope axis } & \multicolumn{2}{|c|}{ Thyrotrope axis } \\
\hline & OR (95\% Cl) & $\mathbf{p}$ & OR (95\% Cl) & $\mathbf{p}$ & OR (95\% Cl) & $\mathbf{p}$ \\
\hline Sex & $\begin{array}{c}1.197 \\
(0.461-3.110)\end{array}$ & 0.712 & $\begin{array}{c}2.539 \\
(1.057-6.098)\end{array}$ & 0.037 & $\begin{array}{c}1.411 \\
(0.672-2.964)\end{array}$ & 0.363 \\
\hline Age & $\begin{array}{c}0.995 \\
(0.957-1.034)\end{array}$ & 0.797 & $\begin{array}{c}0.995 \\
(0.960-1.032)\end{array}$ & 0.782 & $\begin{array}{c}0.973 \\
(0.943-1.004)\end{array}$ & 0.090 \\
\hline Extent of resection & $\begin{array}{c}1.277 \\
(0.474-3.443)\end{array}$ & 0.629 & $\begin{array}{c}0.503 \\
(0.180-1.400)\end{array}$ & 0.188 & $\begin{array}{c}0.542 \\
(0.240-1.226)\end{array}$ & 0.141 \\
\hline Tumor diameter & $\begin{array}{c}1.164 \\
(0.572-2.368)\end{array}$ & 0.676 & $\begin{array}{c}1.405 \\
(0.720-2.742)\end{array}$ & 0.319 & $\begin{array}{c}1.423 \\
(0.808-2.506)\end{array}$ & 0.222 \\
\hline Tumor volume & $\begin{array}{c}1.007 \\
(0.951-1.066) \\
\end{array}$ & 0.809 & $\begin{array}{c}0.993 \\
(0.936-1.053) \\
\end{array}$ & 0.807 & $\begin{array}{c}0.995 \\
(0.949-1.043) \\
\end{array}$ & 0.847 \\
\hline Previous pituitary adenoma resection & $\begin{array}{c}0.449 \\
(0.165-1.220)\end{array}$ & 0.116 & $\begin{array}{c}0.683 \\
(0.256-1.819)\end{array}$ & 0.446 & $\begin{array}{c}0.437 \\
(0.188-1.013)\end{array}$ & 0.054 \\
\hline Pituitary apoplexy & $\begin{array}{c}0.644 \\
(0.182-2.286)\end{array}$ & 0.496 & $\begin{array}{c}1.766 \\
(0.453-6.893)\end{array}$ & 0.413 & $\begin{array}{c}1.167 \\
(0.413-3.294)\end{array}$ & 0.771 \\
\hline
\end{tabular}

$(5,9,14,32)$. In most cases, iMRI can be used to estimate the location, size, and shape of the remnant tumors, as well as identify tumor remnants that cannot be visualized intraoperatively using microscopy or endoscopy, which increases the GTR rate. However, few studies have evaluated the results of iMRI-guided endoscopic TSS for NFPA $(3,6,27)$, and the present study provides the first evidence that highfield iMRI increased the GTR rate for NFPA.

A recent meta-analysis of 5,022 patients with NFPA revealed that the mean postoperative remission rate was $44 \%$ (range: 3-92\%) (30). We observed a similar GTR rate, with GTR considered present for 57 patients based on their first iMRI and a subsequent $21 \%$ increase in the GTR rate (from $42.9 \%$ to $63.9 \%$ ) that was attributable to additional resection, which was performed because the first iMRI identified remnants in 54 of the 133 patients. These results are consistent with those from previous studies regarding TSS aided by high-or low-field iMRI $(1,2,6,8,20,26)$. Never the less, further studies are needed to determine the impact of iMRI on long-term prognoses in patients with NFPAs.

Endocrinological remission is another important goal of endoscopic TSS for NFPAs, as patients with hypopituitarism have a reduced quality of life and life expectancy, even with adequate replacement therapy (10). Furthermore, it takes 3-12 months after surgery to restore anterior pituitary function (33), and GTR significantly influences both tumor control and postoperative recovery from hypopituitarism $(5,18,36)$. However, recent studies have revealed conflicting results regarding the recovery of pituitary function after surgical treatment for NFPAs $(2,3,27,37)$. Moreover, few studies of iMRI have analyzed the association between GTR and postoperative endocrinological changes in each pituitary axis. The present study included 105 patients with preoperative hypopituitarism in one or two pituitary axes, although panhypopituitarism was rare in both the preoperative and postoperative settings. In addition, we identified varying rates of deficiency for the corticotropic axis $(38.3 \%, 51 / 133)$, the thyrotropeaxis $(38.3 \%$, $51 / 133)$, the gonadotropic axis $(66.9 \%, 89 / 133)$, and the growth hormone axis $(14.3 \%, 19 / 133)$. These rates are higher than the previously reported rates $(13,28)$.

After surgery, most patients exhibited some degree of improvement in their preoperative hypopituitarism for the various axes. However, some patients experienced new-onset deficiency or postoperative deterioration in the various axes, which has been described previously. These cases with newonset deficiency or deterioration most commonly involved the thyrotrope axis, which conflicts with the findings of previous studies $(23,34,36)$. In addition, the number of patients with a deficiency in the thyrotrope axis increased. Hypopituitarism can be related to compression of the portal circulation rather than destruction of the normal pituitary gland (24). Furthermore, previous studies have indicated that recovery of pituitary function is associated with patient age, preoperative hormonal deficits, tumor size, the absence of hypertension, intraoperative CSF leak, and stalk-effect hyperprolactinemia $(28,29,36)$.

To analyze the association between pituitary function and GTR, we studied the endocrinological and radiological results for all patients and performed univariate logistic regression analyses that included sex, age, extent of resection, tumor diameter, tumor volume, previous pituitary surgery, and pituitary apoplexy (Table III, IV). Among patients with hypopituitarism of the gonadotrope axis, female patients had higher recovery rates $(p=0.029)$ and lower deficiency rates $(p=0.037)$ than male patients, which is consistent with the previously reported results (3). However, the iMRI-detected 
remnants were not associated with a higher incidence of postoperative hypopituitarism or a lower rate of pituitary axis recovery. These results suggest that relieving pressure on the normal pituitary tissues and portal circulation may accelerate the postoperative recovery of hypopituitarism. However, probing for tumor remnants can damage the pituitary gland and lead to deterioration of its function.

Surgeons attempt to protect pituitary function when performing procedures for patients with NFPA. For example, Linsler et al. (21) recently reported that using an endoscope to intraoperatively distinguish the pituitary gland from the tumor is a feasible method for preserving postoperative pituitary function. In addition, previous studies $(25,31)$ have indicated that the pituitary gland can be easier to detect after administration of a contrast agent because the pituitary rapidly and marked lytakes up the contrast agent. Thus, being able to detect the pituitary gland using iMRI could improve the surgeon's ability to protect its function. However, the pituitary gland drifts during surgery, which can make it difficult to detect. Therefore, further studies are needed to improve our ability to intraoperatively identify normal pituitary glands, which remains a challenge.

The main limitations of iMRI are the extended operation time $(12,27)$ and the false-positive rate $(17)$. The operation time can be minimized to 7-10 min per sequence by obtaining coronal images using T2-weighted turbo spin echo sequences (TE $5,400 \mathrm{~ms}$, TR $98 \mathrm{~ms}$ ) and contrast-enhanced images using T1-weighted spin echo sequences (TE 1,650 ms, TR 3.02 $\mathrm{ms})$, which can be used as intraoperative comparative controls during the surgery for pituitary adenomas. However, false-positive findings may lead to more aggressive probing for remnants, which can result inan increased rate of complications (i.e., CSF leak, new endocrinological deficits, and hemorrhage). The present study revealed a high rate of CSF leak (24/133) and $27.8 \%(15 / 54)$ of the patients who underwent additional resection after the iMRI scan had a CSF leak. However, these events have not limited the increasing tendency to use iMRI.

\section{CONCLUSION}

High-field iMRI was useful for increasing the GTR rate after endoscopic TSS for NFPA. However, the increased GTR rate was not associated with improvement or deterioration of hypopituitarism. Gonadotrope axis deficits were more likely to recover or improve in female patients.

\section{- REFERENCES}

1. Baumann F, Schmid C, Bernays RL: Intraoperative magnetic resonance imaging-guided transsphenoidal surgery for giant pituitary adenomas. Neurosurg Rev 33: 83-90, 2010

2. Bellut $D$, Hlavica M, Muroi $C$, Woernle $C M$, Schmid $C$, Bernays $\mathrm{RL}$ : Impact of intraoperative MRI-guided transsphenoidal surgery on endocrine function and hormone substitution therapy in patients with pituitary adenoma. Swiss Med Wkly 142: w13699, 2012
3. Berkmann S, Fandino J, Muller B, Remonda L, Landolt $\mathrm{H}$ : Intraoperative $\mathrm{MRI}$ and endocrinological outcome of transsphenoidal surgery for non-functioning pituitary adenoma. Acta Neurochir (Wien) 154: 639-647, 2012

4. Berkmann S, Fandino J, Zosso S, Killer HE, Remonda L, Landolt $\mathrm{H}$ : Intraoperative magnetic resonance imaging and early prognosis for vision after transsphenoidal surgery for sellar lesions. J Neurosurg 115: 518-527, 2011

5. Berkmann S, Schlaffer S, Nimsky C, Fahlbusch R, Buchfelder M: Follow-up and long-term outcome of nonfunctioning pituitary adenoma operated by transsphenoidal surgery with intraoperative high-field magnetic resonance imaging. Acta Neurochir (Wien) 156: 2233-2243, 2014

6. Berkmann S, Schlaffer S, Nimsky C, Fahlbusch R, Buchfelder M: Intraoperative high-field MRI for transsphenoidal reoperations of nonfunctioning pituitary adenoma. J Neurosurg 121: 1166-1175, 2014

7. Black PM, Moriarty T, Alexander E 3rd, Stieg P, Woodard EJ, Gleason PL, Martin CH, Kikinis R, Schwartz RB, Jolesz FA: Development and implementation of intraoperative magnetic resonance imaging and its neurosurgical applications. Neurosurgery 41: 831-845, 1997

8. Bohinski RJ, Warnick RE, Gaskill-Shipley MF, Zuccarello M, van Loveren HR, Kormos DW, Tew JM Jr: Intraoperative magnetic resonance imaging to determine the extent of resection of pituitary macroadenomas during transsphenoidal microsurgery. Neurosurgery 49: 1133-1144, 2001

9. Brochier S, Galland F, Kujas M, Parker F, Gaillard S, Raftopoulos C, Young J, Alexopoulou O, Maiter D, Chanson $P$ : Factors predicting relapse of nonfunctioning pituitary macroadenomas after neurosurgery: A study of 142 patients. Eur J Endocrinol 163: 193-200, 2010

10. Bulow B, Hagmar L, Mikoczy Z, Nordstrom CH, Erfurth EM: Increased cerebrovascular mortality in patients with hypopituitarism. Clin Endocrinol (Oxf) 46: 75-81, 1997

11. Chen X, Xu BN, Meng X, Zhang J, Yu X, Zhou D: Dual-room 1.5-T intraoperative magnetic resonance imaging suite with a movable magnet: Implementation and preliminary experience. Neurosurg Rev 35: 95-110, 2012

12. Coburger J, Konig R, Seitz K, Bazner U, Wirtz CR, Hlavac M: Determining the utility of intraoperative magnetic resonance imaging for transsphenoidal surgery: A retrospective study. J Neurosurg 120: 346-356, 2014

13. Comtois R, Beauregard H, Somma M, Serri O, Ark-Jilwan N, Hardy J: The clinical and endocrine outcome to transsphenoidal microsurgery of nonsecreting pituitary adenomas. Cancer 68: 860-866, 1991

14. Greenman Y, Ouaknine G, Veshchev I, Reider G II, Segev Y, Stern N: Postoperative surveillance of clinically nonfunctioning pituitary macroadenomas: Markers of tumour quiescence and regrowth. Clin Endocrinol (Oxf) 58: 763-769, 2003

15. Hardy J, Wigser SM: Trans-sphenoidal surgery of pituitary fossa tumors with televised radiofluoroscopic control. J Neurosurg 23: 612-619, 1965 
16. Hensen J, Henig A, Fahlbusch R, Meyer M, Boehnert M, Buchfelder $\mathrm{M}$ : Prevalence, predictors and patterns of postoperative polyuria and hyponatraemia in the immediate course after transsphenoidal surgery for pituitary adenomas. Clin Endocrinol (Oxf) 50: 431-439, 1999

17. Hirschl RA, Wilson J, Miller B, Bergese S, Chiocca E: The predictive value of low-field strength magnetic resonance imaging for intraoperative residual tumor detection. Clinical article. J Neurosurg 111: 252-257, 2009

18. Jones J, Ruge J: Intraoperative magnetic resonance imaging in pituitary macroadenoma surgery: An assessment of visual outcome. Neurosurg Focus 23: E12, 2007

19. Katznelson L, Alexander JM, Klibanski A: Clinical review 45: Clinically nonfunctioning pituitary adenomas. J Clin Endocrinol Metab 76: 1089-1094, 1993

20. Kim EH, Oh MC, Kim SH: Application of low-field intraoperative magnetic resonance imaging in transsphenoidal surgery for pituitary adenomas: Technical points to improve the visibility of the tumor resection margin. Acta Neurochir (Wien) 155: 485-493, 2013

21. Linsler S, Hero-Gross R, Friesenhahn-Ochs B, Sharif $S$, Lammert F, Oertel J: Preservation of hormonal function by identifying pituitary gland at endoscopic surgery. J ClinNeurosci 43: 240-246, 2017

22. Liu J, Li C, Xiao Q, Gan C, Chen X, Sun W, Li X, Xu Y, Chen J, Shu K, Lei T: Comparison of pituitary adenomas in elderly and younger adults: Clinical characteristics, surgical outcomes, and prognosis. J Am Geriatr Soc 63: 1924-1930, 2015

23. Losa M, Donofrio CA, Barzaghi R, Mortini P: Presentation and surgical results of incidentally discovered nonfunctioning pituitary adenomas: Evidence for a better outcome independently of other patients' characteristics. Eur J Endocrinol 169: 735742,2013

24. Marazuela M, Astigarraga B, Vicente A, Estrada J, Cuerda C, García-Uría J, Lucas T: Recovery of visual and endocrine function following transsphenoidal surgery of large nonfunctioning pituitary adenomas. J Endocrinol Invest 17: 703-707, 1994

25. Miki Y, Matsuo M, Nishizawa S, Kuroda Y, Keyaki A, Makita $\mathrm{Y}$, Kawamura J: Pituitary adenomas and normal pituitary tissue: Enhancement patterns on gadopentetate-enhanced MR imaging. Radiology 177: 35-38, 1990

26. Nimsky C, Ganslandt O, Keller Bv, Romstock J, Fahlbusch R: Intraoperative high-field-strength MR imaging: Implementation and experience in 200 patients. Radiology 233: 67-78, 2004

27. Nimsky C, von Keller B, Ganslandt O, Fahlbusch R: Intraoperative high-field magnetic resonance imaging in transsphenoidal surgery of hormonally inactive pituitary macroadenomas. Neurosurgery 59: 105-114, 2006
28. Nomikos P, Ladar C, Fahlbusch R, Buchfelder M: Impact of primary surgery on pituitary function in patients with nonfunctioning pituitary adenomas - a study on 721 patients. Acta Neurochir (Wien) 146: 27-35, 2004

29. Robenshtok E, Benbassat CA, Hirsch D, Tzvetov G, Cohen ZR, Iraqi HM, Gorshtein A, Toledano Y, Shimon I: Clinical course and outcome of nonfunctioning pituitary adenomas in the elderly compared with younger age groups. Endocr Pract 20: 159-164, 2014

30. Roelfsema F, Biermasz NR, Pereira AM: Clinical factors involved in the recurrence of pituitary adenomas after surgical remission: A structured review and meta-analysis. Pituitary 15: 71-83, 2012

31. Steiner E, Imhof H, Knosp E: Gd-DTPA enhanced high resolution MR imaging of pituitary adenomas. Radiographics 9: 587-598, 1989

32. Sylvester PT, Evans JA, Zipfel GJ, Chole RA, Uppaluri R, Haughey $\mathrm{BH}$, Getz $\mathrm{AE}$, Silverstein J, Rich KM, Kim $\mathrm{AH}$, Dacey RG, Chicoine MR: Combined high-field intraoperative magnetic resonance imaging and endoscopy increase extent of resection and progression-free survival for pituitary adenomas. Pituitary 18: 72-85, 2015

33. Tominaga A, Uozumi T, Arita K, Kurisu K, Yano T, Hirohata $\mathrm{T}$ : Anterior pituitary function in patients with nonfunctioning pituitary adenoma: Results of longitudinal follow-up. Endocr $\mathrm{J}$ 42: 421-427, 1995

34. Vargas G, Gonzalez B, Ramirez C, Ferreira A, Espinosa E, Mendoza V, Guinto G, Lopez-Felix B, Zepeda E, Mercado M: Clinical characteristics and treatment outcome of 485 patients with nonfunctioning pituitary macroadenomas. Int $\mathrm{J}$ Endocrinol 2015: 756069, 2015

35. Vitaz TW, Inkabi KE, Carrubba CJ: Intraoperative MRI for transphenoidal procedures: Short-term outcome for 100 consecutive cases. ClinNeurol Neurosurg 113: 731-735, 2011

36. Webb SM, Rigla M, Wagner A, Oliver B, Bartumeus F: Recovery of hypopituitarism after neurosurgical treatment of pituitary adenomas. J Clin Endocrinol Metab 84: 3696-3700, 1999

37. Wichers-Rother M, Hoven S, Kristof RA, Bliesener N, Stoffel-Wagner B: Non-functioning pituitary adenomas: Endocrinological and clinical outcome after transsphenoidal and transcranial surgery. Exp Clin Endocrinol Diabetes 112: 323-327, 2004

38. Zada G, Lin N, Laws ER Jr: Patterns of extrasellar extension in growth hormone-secreting and nonfunctional pituitary macroadenomas. Neurosurg Focus 29: E4, 2010

39. Zaidi HA, Awad AW, Bohl MA, Chapple K, Knecht L, Jahnke $\mathrm{H}$, White WL, Little AS: Comparison of outcomes between a less experienced surgeon using a fully endoscopic technique and a very experienced surgeon using a microscopic transsphenoidal technique for pituitary adenoma. J Neurosurg 124: 596-604, 2016 